\title{
A Clinical Study on the Initial Assessment of Arterial Lactate and Base Deficit as Predictors of Outcome in Trauma Patients
}

\author{
Rameshbabu Homanna Javali, Prithvishree Ravindra'1, Akkamahadevi Patil, Madhu Srinivasarangan, Harshit Mundada², S. B. Adarsh, S. Nisarg \\ Department of Emergency Medicine, JSS Medical College and Hospital, Mysore, ${ }^{1}$ Department of Emergency Medicine, Kasturba Medical College, Manipal, \\ 2Department of Emergency Medicine, St. John's Medical College and Hospital, Bengaluru, Karnataka, India
}

\section{Abstract}

Background: Trauma is a leading cause of mortality in India. Outcomes can be improved by early recognition of hemorrhagic shock and expedited management. At present, we rely on traditional vital signs, which are not sensitive measures. Point of care biochemical markers have been emerging as prognostic markers in trauma, but have not been studied in Indian setting. Aims: This study aims to study the association between arterial lactate and base deficit (BD) at emergency department (ED) admission and $24 \mathrm{~h}$ outcome in trauma patients at risk of hemodynamic compromise. Materials and Methods: This was a prospective observational study on 100 trauma patients at risk of hemodynamic compromise in tertiary care center ED. Arterial blood gas analysis at admission and $24 \mathrm{~h}$ outcomes were noted and statistically analyzed. Results: Arterial lactate $\geq 4 \mathrm{mmol} / \mathrm{L}$ (sensitivity $100 \%$ and specificity $85.9 \%$ ), BD $\geq 12 \mathrm{mEq} / \mathrm{L}$ (sensitivity $87.5 \%$ and specificity $82.6 \%$ ) had more sensitivity than vital signs for predicting $24 \mathrm{~h}$ mortality. Higher lactate and BD were associated with increased blood transfusion requirement. Best cutoff values for predicting transfusion were lactate $\geq 2.9 \mathrm{mmol} / \mathrm{L}$ (sensitivity $65.2 \%$ and specificity $90.7 \%$ ), BD $\geq 8 \mathrm{mEq} / \mathrm{L}$ (sensitivity $78.3 \%$ and specificity $75.9 \%$ ). BD-based classification was comparable to ATLS classification in predicting mortality and determining transfusion requirements. Patients with higher arterial lactate and BD were found to have higher 24 h Intensive Care Unit (ICU) admission. Conclusion: Emergency admission arterial lactate and Base Deficit are useful predictors of mortality, need for blood transfusion and ICU admission at $24 \mathrm{~h}$. It can be used to triage, identify shock early, assess transfusion requirement, and prognosticate trauma patients.

Keywords: Base deficit, blood transfusion, lactate, mortality, trauma

\section{INTRODUCTION}

Worldwide, trauma is a leading cause of mortality and morbidity. ${ }^{[1]}$ India features amongst the countries with highest age-standardized mortality rates due to injuries (116 per 100,000 population). ${ }^{[2]}$ The golden hour of care after injury is characterized by rapid assessment and resuscitation. It is aimed at the early recognition of hemorrhagic shock and early intervention, which forms the centerpiece of ATLS. ${ }^{[3]}$

At present, we rely on traditional vital signs such as blood pressure (BP) and heart rate (HR) to guide the initial workup of injured patients ${ }^{[4]} \mathrm{BP}$ is usually well maintained and may only fall after $30 \%-40 \%$ of the circulating volume has been lost. ${ }^{[3]}$ Tachycardia is not a reliable sign to recognize shock. Therefore, vital signs should only be surrogate markers and not direct measures of oxygen delivery. Better marker for

\begin{tabular}{|l|l|}
\hline \multicolumn{3}{|c|}{ Access this article online } \\
\hline Quick Response Code: & Website: \\
& www.ijccm.org \\
\hline
\end{tabular}

the presence and extent of ongoing hemorrhage may be the actual metabolic products of tissue hypoperfusion such as base deficit (BD) and lactate.

Emergency care system is in its infancy in India. ${ }^{[5]}$ There is a lacuna of studies regarding trauma care and predictors of outcome in trauma. Our study aims to help bridge this gap in knowledge and assess whether a point of care arterial blood gas $(\mathrm{ABG})$ analysis in the emergency department (ED) can help us detect shock early and manage trauma optimally.

Address for correspondence: Dr. Prithvishree Ravindra, Department of Emergency Medicine, Kasturba Medical College, Manipal, Udupi, Karnataka - 576 104, India. E-mail: prithvishree@gmail.com

This is an open access article distributed under the terms of the Creative Commons Attribution-NonCommercial-ShareAlike 3.0 License, which allows others to remix, tweak, and build upon the work non-commercially, as long as the author is credited and the new creations are licensed under the identical terms.

For reprints contact: reprints@medknow.com

How to cite this article: Javali RH, Ravindra P, Patil A, Srinivasarangan M, Mundada $\mathrm{H}$, Adarsh SB, et al. A clinical study on the initial assessment of arterial lactate and base deficit as predictors of outcome in trauma patients. Indian J Crit Care Med 2017;21:719-25. 


\section{Objectives}

The objective of this study is to study the association between ED admission arterial lactate, BD and the $24 \mathrm{~h}$ mortality, blood transfusion requirement and Intensive Care Unit (ICU) admission in trauma patients at risk of hemodynamic compromise.

\section{Materials and Methods}

\section{Study design}

Prospective observational study carried out over a period of 18 months on trauma patients presenting to the ED of a tertiary care center. After applying the inclusion and exclusion criteria, a total of 100 patients were eligible to participate in our study.

\section{Inclusion criteria}

Poly/isolated trauma patients at risk of hemodynamic compromise such as:

a. Penetrating trauma to chest, abdomen, or pelvis

b. Pelvis fracture

c. Shaft of femur fracture

d. Blunt injury to abdomen or chest.

\section{Exclusion criteria}

1. Presenting after $12 \mathrm{~h}$ of injury

2. Severe head injuries (arrival Glasgow coma scale $\leq 8$ ) with intracranial bleed

3. Blood transfusion before arrival

4. Cardiac arrest before arrival

5. Transferred after stabilization and resuscitation from a tertiary care center

6. Discharged against medical advice within $24 \mathrm{~h}$ of admission

7. Conditions predisposing to altered lactate levels: heart failure, respiratory failure, liver disease, severe dehydration, patients on metformin/antiretroviral therapy

8. Not willing to participate.

\section{Method of study}

After taking informed consent, ED admission investigations including $\mathrm{Hb}$, packed cell volume, and $\mathrm{ABG}$ were done. Demographic details, vital signs, type and nature of injury, ATLS Classification were noted.

Patients were followed up for a period of $24 \mathrm{~h}$, and the following outcomes were noted:

1. Mortality

2. Blood transfusion received

3. ICU admission.

The above details were statistically analyzed and results were calculated.

Summary statistics was done by measuring mean, median, standard deviation, and proportions. Inferential statistics was done using Chi-square test, independent t-test, receiver operating characteristic (ROC) curve, sensitivity, specificity, positive predictive value (PPV), negative predictive value
(NPV), ANOVA, and Mann-Whitney test. $P<0.05$ was considered statistically significant.

\section{RESULTS}

Demographic analysis revealed $53 \%$ of the study population was in the age group of $21-40$ years. At presentation, $9 \%$ had hypotension, $34 \%$ had tachycardia, $26 \%$ had shock index $>1$, and $31 \%$ had $\mathrm{Hb}<11 \mathrm{~g} / \mathrm{dl}$. The overall $24 \mathrm{~h}$ mortality in our study population was $8 \%$. Forty-six percent of the patients required blood transfusion and $48 \%$ required ICU admission in $24 \mathrm{~h}$.

\section{Outcome: 24 h mortality}

ROC curve analysis showed that area under the curve (AUC) for arterial lactate was 0.955 (95\% confidence interval [CI], $0.914-0.997$ ) and BD was 0.898 (95\% CI, 0.813-0.983) for $24 \mathrm{~h}$ mortality [Figure 1].

Difference between $24 \mathrm{~h}$ mortality for arterial lactate $<4 \mathrm{mmol} / \mathrm{L}(0 \%)$ and $\geq 4 \mathrm{mmol} / \mathrm{L}(38.1 \%)$ was statistically significant $(P<0.001)$ [Figure 2].

ED admission arterial lactate $\geq 4 \mathrm{mmol} / \mathrm{L}$ had sensitivity of $100 \%(95 \% \mathrm{CI}, 67.56 \%-100 \%)$ and specificity of $85.9 \%$ (95\% CI, $77.31 \%-91.55 \%$ ) for $24 \mathrm{~h}$ mortality. PPV was $38.1 \%$ (95\% CI, 20.75\%-59.12\%) and NPV was $100 \%$ (95\% CI, 95.36\%-100\%).

ROC curve analysis revealed a cut off of $B D \geq 12 \mathrm{mEq} / \mathrm{L}$ has a sensitivity of $87.5 \%$ (95\% CI, 52.91-97.76) and specificity of $82.6 \%$ (95\% CI, 73.6.89) for $24 \mathrm{~h}$ mortality. The PPV was $30.43 \%(95 \% \mathrm{CI}, 15.6-50.87)$ and NPV was $98.7 \%$ (95\% CI, 93\%-99.77\%).

\section{Outcome: 24 h blood transfusion}

ROC curve analysis showed AUC for lactate was 0.790 (95\% CI, 0.697-0.884) and BD was 0.787 (95\% CI, 0.694-0.879) for $24 \mathrm{~h}$ blood transfusion requirement [Figure 3].

Using the ROC curve, we arrived at the cutoff value of $\geq 2.9 \mathrm{mmol} / \mathrm{L}$ to be most appropriate for predicting transfusion.

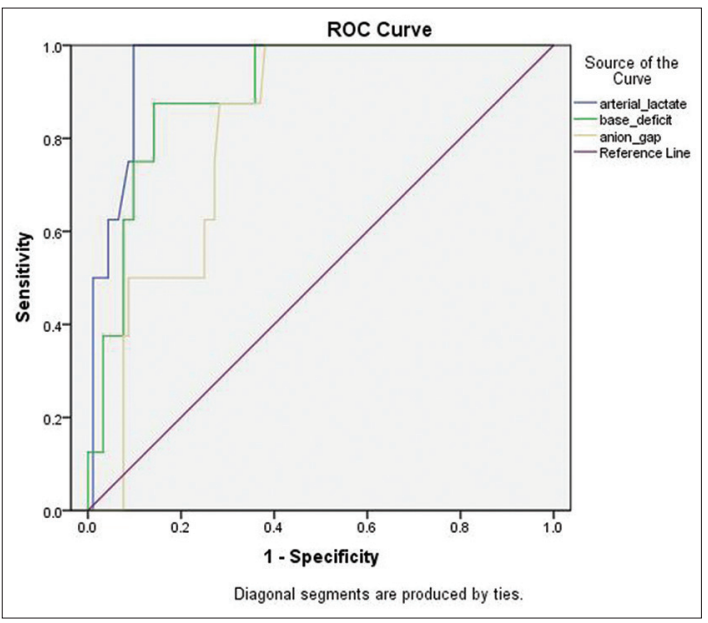

Figure 1: Receiver operating characteristic curve analysis for $24 \mathrm{~h}$ mortality 
ED admission arterial lactate $\geq 2.9 \mathrm{mmol} / \mathrm{L}$ had sensitivity $65.2 \%$ (95\% CI, 50.77\%-77.32\%), specificity $90.7 \%$ (95\% CI, $80.09 \%-95.98 \%)$, PPV $85.71 \%$ (95\% CI, 70.62\%-93.74\%), NPV 75.38\% (95\% CI, 63.69\%-84.24\%), and diagnostic accuracy $79 \%$ (95\% CI, 70.02\%-85.83\%).

Difference in blood requirement among the patients with lactate $<2.9 \mathrm{mmol} / \mathrm{L}(24.6 \%)$ and lactate $\geq 2.9 \mathrm{mmol} / \mathrm{L}(85.7 \%)$ was stasstistically significant $(P<0.001)$ [Figure 4].

Using the ROC curve, we arrived at the cut off of BD $8 \mathrm{mEq} / \mathrm{L} . \mathrm{BD} \geq 8 \mathrm{mEq} / \mathrm{L}$ had sensitivity of $78.3 \%(95 \%$ CI, $64.4 \%-87.7 \%)$ and specificity of $75.9 \%(95 \% \mathrm{CI}$, $63 \%-85.4 \%)$, PPV of $73.5 \%$ (95\% CI, 59.8\%-83.8\%) and NPV of $80.4 \%(95 \%$ CI, $67.5 \%-89 \%)$ and Diagnostic accuracy of $77 \%(95 \% \mathrm{CI}, 67.8 \%-84.1 \%)$.

Using BD-based classification, there was higher mortality and blood transfusion requirement in class 3 and Class 4 . These data were statistically significant [Table 1 and Figures 5, 6].

The mortality and transfusion rates linearly increased through class 1 to class 4 of ATLS classification and the relationship was statistically significant.

\section{Outcome: Intensive Care Unit admission}

There was a statistically significant difference in $24 \mathrm{~h} \mathrm{ICU}$ admission in patients with lactate $<4 \mathrm{mmol} / \mathrm{L}(25.9 \%)$ and $\geq 4 \mathrm{mmol} / \mathrm{L}(86.9 \%) .(P<0.001)$ [Figure 7 ].

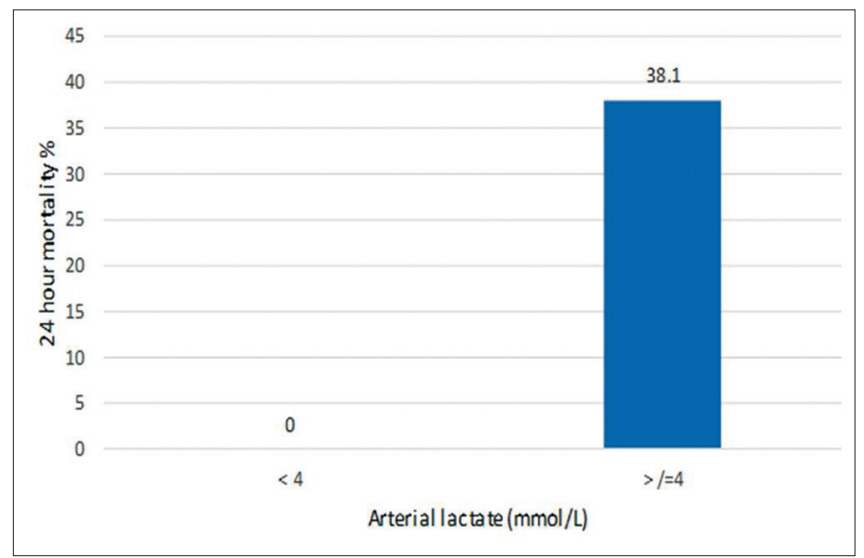

Figure 2: Twenty-four hours mortality rate for different values of arterial lactate

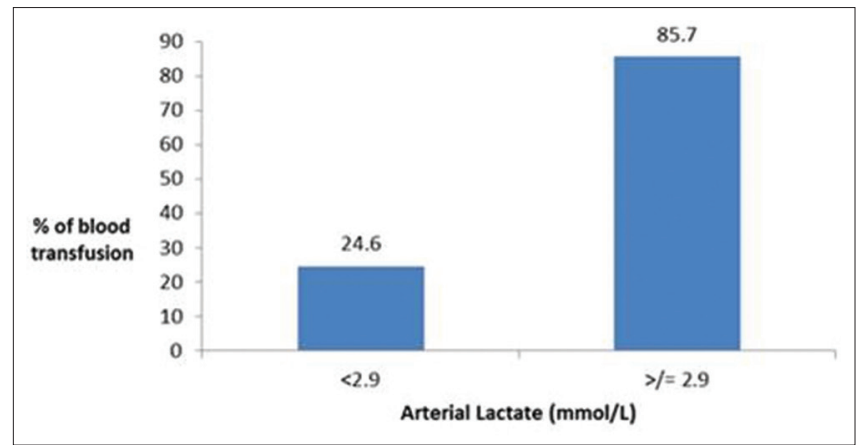

Figure 4: Blood transfusion requirement in $24 \mathrm{~h}$ at different values of arterial lactate
In patients with $\mathrm{BD}<12 \mathrm{mEq} / \mathrm{L}, 35.1 \%$ patients required $\mathrm{ICU}$ admission. In patients with arterial lactate $\geq 12 \mathrm{mmol} / \mathrm{L}, 91.3 \%$ required ICU admission. This difference was statistically significant $(P<0.001)$ [Figure 8].

\section{Predictors of $24 \mathrm{~h}$ mortality}

Although hypotension is $95.6 \%$ specific for $24 \mathrm{~h}$ mortality, its sensitivity is only $62.5 \%$. Tachycardia and shock index have a sensitivity of $87.5 \%$, which is similar to the BD of cutoff value $>12 \mathrm{mEq} / \mathrm{L}$ (chosen according to the ROC curve). Arterial lactate $>/ 4 \mathrm{mmol} / \mathrm{L}$ has the highest sensitivity among the parameters, with specificity of $85.9 \%$ [Table 2 and Figure 9].

\section{Predictors of $24 \mathrm{~h}$ blood transfusion requirement}

Hypotension has sensitivity of $17.39 \%$ for $24 \mathrm{~h}$ blood transfusion. Tachycardia and $\mathrm{Hb}$ at admission $<11 \mathrm{~g} / \mathrm{dl}$ has sensitivity of $50 \%$.

Arterial lactate $>2.9 \mathrm{mmol} / \mathrm{L}(65.22 \%)$ and $\mathrm{BD} \geq 8 \mathrm{mEq} / \mathrm{L}$ $(78.26 \%)$ has greater sensitivity in predicting requirement of $24 \mathrm{~h}$ blood transfusion [Table 3 and Figure 10].

Outcomes arterial lactate $\geq 4 \mathrm{mmol} / \mathrm{L}$ and $\mathrm{BD} \geq 12 \mathrm{mEq} / \mathrm{L}$ are summarized in Table 4.

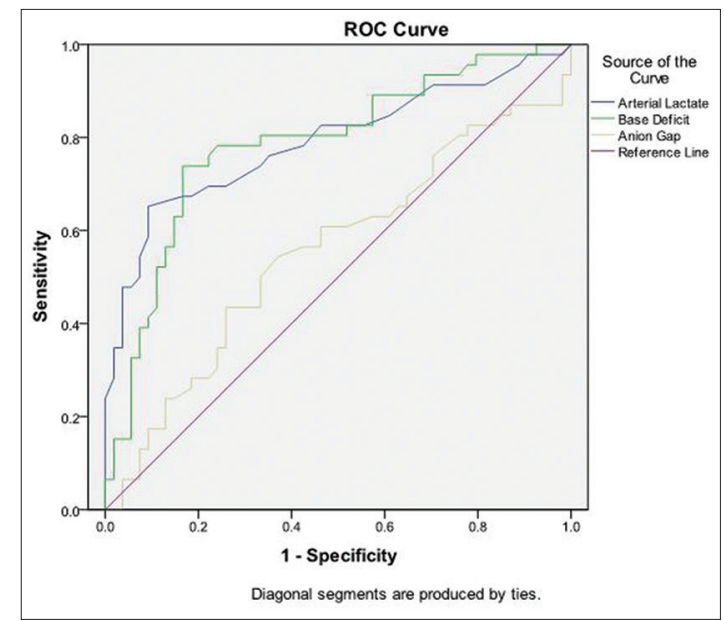

Figure 3: Receiver operating characteristic curve analysis for requirement of blood transfusion in $24 \mathrm{~h}$

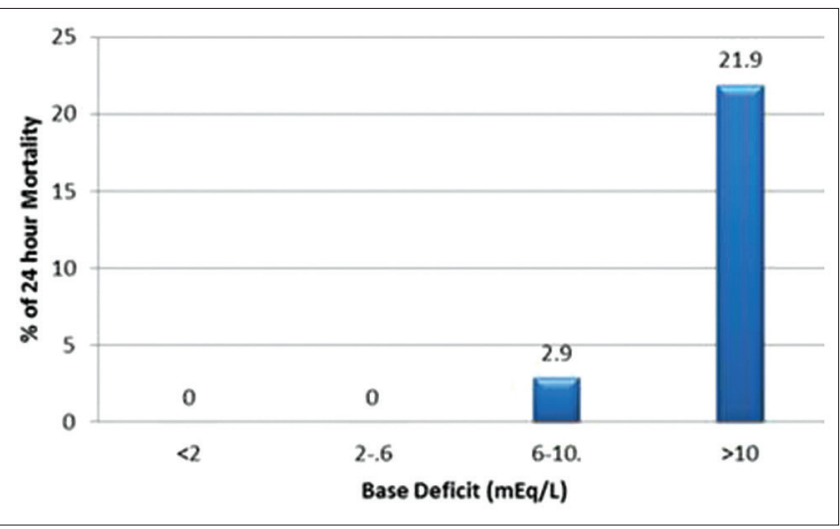

Figure 5: Twenty-four-hour mortality rates in the various classes of the base deficit-based classification 


\begin{tabular}{|c|c|c|c|c|c|c|}
\hline $\begin{array}{l}\text { BD value } \\
(\mathrm{mEq} / \mathrm{L})\end{array}$ & $\begin{array}{l}\text { BD-based } \\
\text { classification class }\end{array}$ & $\begin{array}{l}\text { Number of } \\
\text { patients }\end{array}$ & $\begin{array}{c}\text { Number of } \\
\text { deaths in } 24 \mathrm{~h}\end{array}$ & $\begin{array}{l}\text { Percentage of } \\
24 \text { h mortality }\end{array}$ & $\begin{array}{l}\text { Number requiring } \\
\text { blood in first } 24 \mathrm{~h}\end{array}$ & $\begin{array}{l}\text { Percentage of patients } \\
\text { requiring blood transfusion }\end{array}$ \\
\hline$<2$ & 1 (no shock) & 4 & 0 & 0 & 0 & 0 \\
\hline $2-6$ & 2 (mild shock) & 30 & 0 & 0 & 8 & 26.7 \\
\hline $6-10$ & 3 (moderate shock) & 33 & 1 & 2.9 & 13 & 38.2 \\
\hline$>10$ & 4 (severe shock) & 25 & 7 & 21.9 & 25 & 78.1 \\
\hline
\end{tabular}

BD: Base deficit

Table 2: Sensitivity and specificity of various clinical and laboratory parameters to predict $24 \mathrm{~h}$ mortality

\begin{tabular}{|c|c|c|c|c|}
\hline \multirow[t]{3}{*}{ Parameter } & \multicolumn{4}{|c|}{24 h mortality } \\
\hline & \multicolumn{2}{|c|}{ Sensitivity } & \multicolumn{2}{|c|}{ Specificity } \\
\hline & Percentage & $95 \% \mathrm{Cl}$ & Percentage & $95 \% \mathrm{Cl}$ \\
\hline Hypotension (SBP $<90 \mathrm{mmHg}$ ) & 62.5 & $30.57-86.32$ & 95.6 & $89.35-98.3$ \\
\hline Tachycardia $(\mathrm{HR}>100 / \mathrm{min})$ & 87.5 & $52.91-97.76$ & 90.3 & $81.26-95.21$ \\
\hline $\mathrm{Hb}$ at admission $<11 \mathrm{~g} / \mathrm{dL}$ & 62.5 & $30.57-86.32$ & 71.7 & $61.81-79.92$ \\
\hline Shock index $>1$ & 87.5 & $52.91-97.76$ & 79.4 & $69.98-86.36$ \\
\hline Arterial lactate $\geq 4 \mathrm{mmol} / \mathrm{L}$ & 100 & $67.56-100$ & 85.9 & $77.31-91.55$ \\
\hline $\mathrm{BD} \geq 12 \mathrm{mEq} / \mathrm{L}$ & 87.5 & $52.91-97.76$ & 82.6 & 73.6-89 \\
\hline Anion gap $\geq 12 \mathrm{mEq} / \mathrm{L}$ & 50 & $21.52-78.48$ & 77.2 & $67.61-84.56$ \\
\hline
\end{tabular}

CI: Confidence interval; SBP: Systolic blood pressure; HR: Heart rate; BD: Base deficit; Hb: Haemoglobin

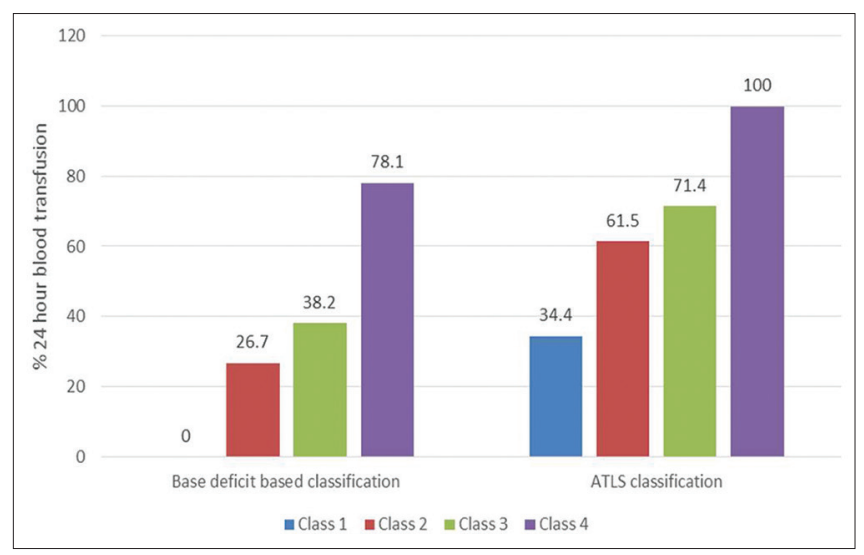

Figure 6: Comparison of $24 \mathrm{~h}$ blood transfusion requirement in various classes of base deficit-based classification of shock and ATLS classification

\section{Discussion}

The measurement of ED admission arterial lactate and BD were found to be useful in predicting $24 \mathrm{~h}$ mortality in our study. This was depicted by ROC curve analysis.

In our study, using the ROC curve, a cutoff value of $\geq 4 \mathrm{mmol} / \mathrm{L}$ for arterial lactate had sensitivity of $100 \%(95 \% \mathrm{CI}$, $67.56 \%-100 \%$ ). There has been controversy over what cutoff value to use for arterial lactate. One study suggests that it should probably lie between 2 and $2.5 \mathrm{mmol} / \mathrm{L} .{ }^{[6]}$ Okello et al. found that patients with lactate above $2.0 \mathrm{mmol} / \mathrm{L}$ had 1.19 times risk of death within $72 \mathrm{~h}$ per unit increase in lactate. ${ }^{[7]}$

Although some studies use a lower cutoff, we found that using a cutoff of $2 \mathrm{mmol} / \mathrm{L}$, our specificity for $24 \mathrm{~h}$ mortality decreased

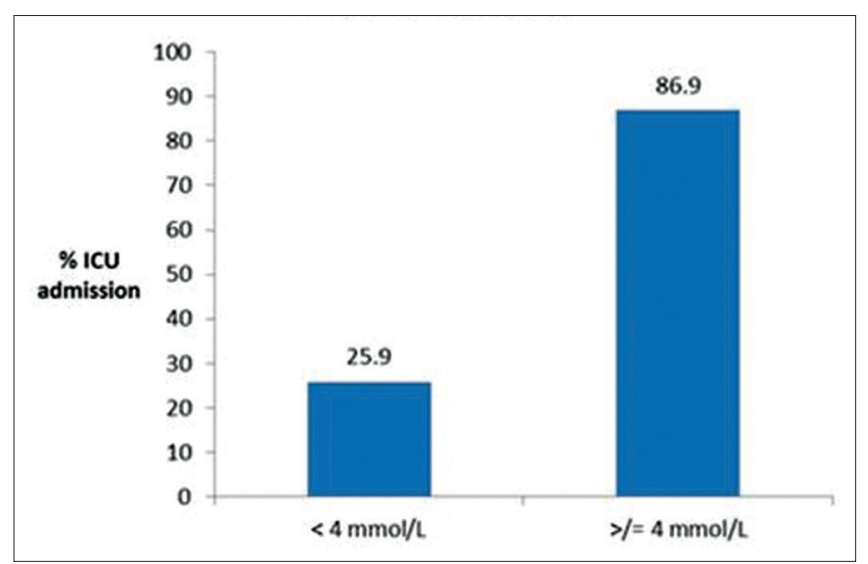

Figure 7: Percentage of patients requiring Intensive Care Unit admission in $24 \mathrm{~h}$ at different levels of arterial lactate

to $40.2 \%$. A slight elevation in lactate maybe due to the stress response to trauma and may not be indicative of increased risk of mortality. By using a higher cutoff of $4 \mathrm{mmol} / \mathrm{L}$, we were able to get high sensitivity, and our specificity increased to $85.9 \%$. This can be a more appropriate cutoff.

Odom et al. also found that lactate $\geq 4.0 \mathrm{mmol} / \mathrm{L}$ had mortality of $18.8 \%$ (95\% CI, $15.7 \%-21.9 \%$ ) and the initial lactate level strongly correlated with mortality. ${ }^{[8]}$

In our study, lactate measurement had higher sensitivity than hypotension and tachycardia for predicting $24 \mathrm{~h}$ mortality. Therefore, lactate will aid us to detect patients with occult hypoperfusion.

Twenty-four-hour PRBC requirement is both a novel independent predictor of and has the greatest correlation 
Table 3: Specificity and sensitivity for $24 \mathrm{~h}$ blood transfusion requirement for various clinical and laboratory parameters

\begin{tabular}{|c|c|c|c|c|}
\hline \multirow[t]{3}{*}{ Parameter } & \multicolumn{4}{|c|}{$24 \mathrm{~h}$ blood transfusion requirement } \\
\hline & \multicolumn{2}{|c|}{ Sensitivity } & \multicolumn{2}{|c|}{ Specificity } \\
\hline & Percentage & $95 \% \mathrm{Cl}$ & Percentage & $95 \% \mathrm{Cl}$ \\
\hline Hypotension (SBP $<90 \mathrm{mmHg}$ ) & 17.39 & $9.1-30.7$ & 98.2 & $90.2-99.7$ \\
\hline Tachycardia (HR >100/min) & 50 & $36.1-63.8$ & 79.6 & $67.1-88.1$ \\
\hline $\mathrm{Hb}$ at admission $<11 \mathrm{~g} / \mathrm{dL}$ & 50 & $36.12-63.88$ & 85.2 & $73.4-92.3$ \\
\hline Shock index $>1$ & 43.5 & $30.21-57.75$ & 85.2 & $77.81-94.81$ \\
\hline Arterial lactate $\geq 2.9 \mathrm{mmol} / \mathrm{L}$ & 65.22 & $50.77-77.32$ & 90.74 & 80.09-95.98 \\
\hline $\mathrm{BD} \geq 8 \mathrm{mmol} / \mathrm{L}$ & 78.26 & $64.43-87.74$ & 75.93 & $63.05-85.36$ \\
\hline Anion gap $>12 \mathrm{mEq} / \mathrm{L}$ & 28.3 & $17.32-42.55$ & 77.8 & $65.06-86.8$ \\
\hline
\end{tabular}

CI: Confidence interval; SBP: Systolic blood pressure; HR: Heart rate; BD: Base deficit; Hb: Haemoglobin

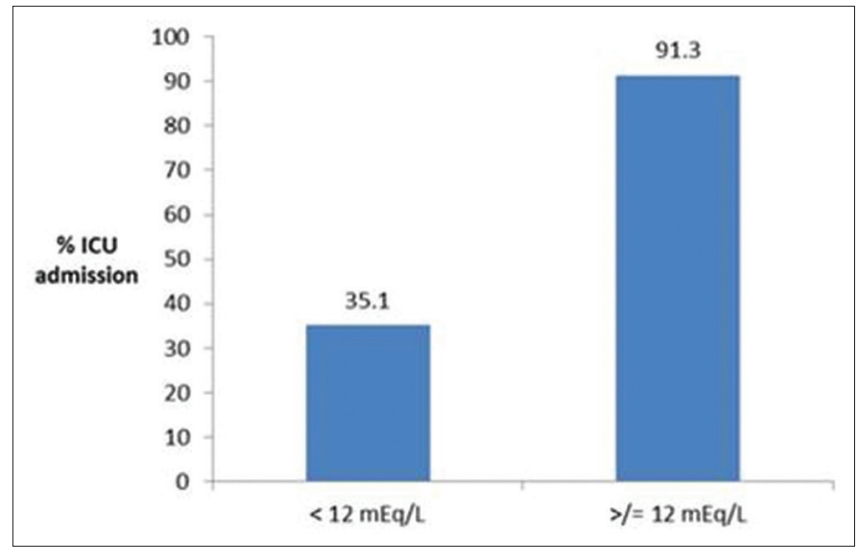

Figure 8: Percentage of patients requiring Intensive Care Unit admission in $24 \mathrm{~h}$ at different levels of base deficit

to mortality in adult trauma patients when compared to injury severity score and shock index. ${ }^{[9]}$ Our study showed that measurement of ED admission arterial lactate and BD is useful in predicting requirement of blood transfusion in $1^{\text {st }} 24 \mathrm{~h}$ of admission. Arterial lactate $\geq 2.9 \mathrm{mmol} / \mathrm{L}$ (sensitivity $65.2 \%$ and specificity $90.6 \%$ ) and $\mathrm{BD} \geq 8 \mathrm{mmol} / \mathrm{L}$ (sensitivity $78.3 \%$ and specificity $75.9 \%$ ) were found to be more sensitive measures than hypotension (sensitivity $17.39 \%$ and specificity $98.2 \%$ ) and tachycardia (sensitivity $50 \%$ and specificity $79.6 \%$ ) to predict blood transfusion requirement in $24 \mathrm{~h}$.

Brooke et al. studied hemodynamically normal trauma patients and found that an admission lactate of $>4 \mathrm{mmol} / \mathrm{L}$ had a greater need for massive transfusion (MT) and greater blood requirement. ${ }^{[10]}$

BD was previously a widely used biomarker in critical patients. Not only has it been found to correlate with severity of injury and degree of hemorrhage, ${ }^{[11]}$ but also it has been advocated as a marker of resuscitation adequacy ${ }^{[12]}$ This assessment of metabolic acidosis has been incorporated into the standard information that is reported on a routine blood gas analysis. However, due to various confounding factors, reliability of $\mathrm{BD}$ was questioned. Recently, there has been a renaissance in the use of $\mathrm{BD}$ for the initial assessment of trauma patients. ${ }^{[13]}$

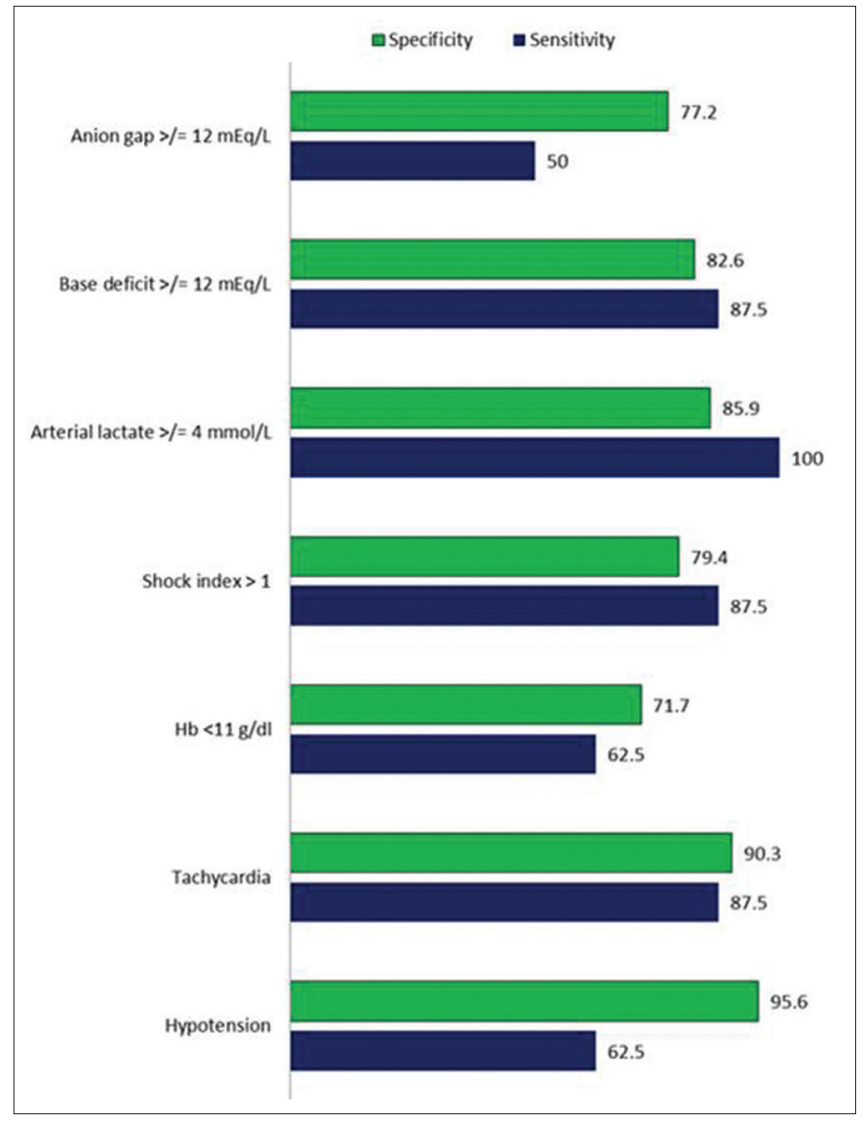

Figure 9: Sensitivity and specificity of various clinical and laboratory parameters to predict $24 \mathrm{~h}$ mortality

A BD-based classification for hypovolemic shock in trauma patients has also been designed and validated. ${ }^{[13]}$

In our study, we found that $\mathrm{BD} \geq 12 \mathrm{mEq} / \mathrm{L}$ has a sensitivity of $87.5 \%$ (95\% CI, 52.91-97.76) and specificity of $82.6 \%$ (95\% CI, 73.6-89) for $24 \mathrm{~h}$ mortality. Saad et al. found that in polytrauma patients, the cutoff for BD more than $5.6 \mathrm{mEq} / \mathrm{L}$ had $64 \%$ sensitivity, $93 \%$ specificity for predicting mortality. They recommended it to be used with other scoring systems for predicting mortality. ${ }^{[14]}$ Mofidi et al. studied BD in abdominal trauma patients and found a cutoff point of $6 \mathrm{mEq} / \mathrm{L}$ has $88.2 \%$ sensitivity and $95.2 \%$ specificity, with positive and NPVs of 
$79 \%$ and $97.5 \%$, respectively. ${ }^{[15]}$ In our study, when we chose cutoff of $6 \mathrm{mEq} / \mathrm{L}$, we had high sensitivity (100\%), but low specificity (37\%). Therefore, we derived the cutoff of $12 \mathrm{mEq} / \mathrm{L}$ to achieve better specificity [Table 5].

The resurgence of interest in BD as an early marker in traumatic shock has led to a BD-based classification of hypovolemic shock in trauma. We found that BD-based classification could be used to predict mortality and $24 \mathrm{~h}$ blood transfusion.

Mutschler et al. studied patients identified from the Trauma registry to validate this $\mathrm{BD}$ classification. They found that $\mathrm{BD}$ distinguished more precisely between patients at risk of dying than the current ATLS classification of hypovolemic shock. They also found that when the two approaches to classify the extent of hypovolemic shock upon ED admission were compared (ATLS and BD based), the new BD-based classification displayed a higher accuracy for discriminating the need for early blood products than the current ATLS classification of hypovolemic shock. Through Groups II to $\mathrm{IV}$, the percentage of patients who had received at least 1 blood unit during early ED resuscitation was significantly higher compared with patients classified according to ATLS. Regarding the need for blood products, they recommended to watch in class I, consider in class II, act in class III, and be prepared for MT in class IV of BD-based classification. ${ }^{[13]}$

One of the important decisions in the ED is the disposition of the patient.

We found that patients' with higher admission arterial lactate and BD had increased ICU admission in $24 \mathrm{~h}$.

Brooke et al. studied hemodynamically normal patients and found that admission lactate of $>4 \mathrm{mmol} / \mathrm{L}$ along with having increased mortality, longer hospital length of stay, greater need for MT and greater blood requirement, had a longer ICU stay. They concluded that in hemodynamically normal trauma patients, the admission lactate of $>4 \mathrm{mmol} / \mathrm{L}$ is a robust predictor of longer ICU stay and poor outcomes. ${ }^{[10]}$
The standard triage criterion for trauma patients has been found to result in overtriage rates of $30 \%-50 \%$ to achieve undertriage rates of $10 \%$. This large number of patients may stress trauma center resources. Lavery et al. found that patients with venous lactate $\geq 2 \mathrm{mmol} / \mathrm{L}$ had significantly increased relative risks of admission to the ICU, and length of stay $>2$ days. This study found no significant difference between arterial lactate and venous lactate measured; therefore both the samples could be

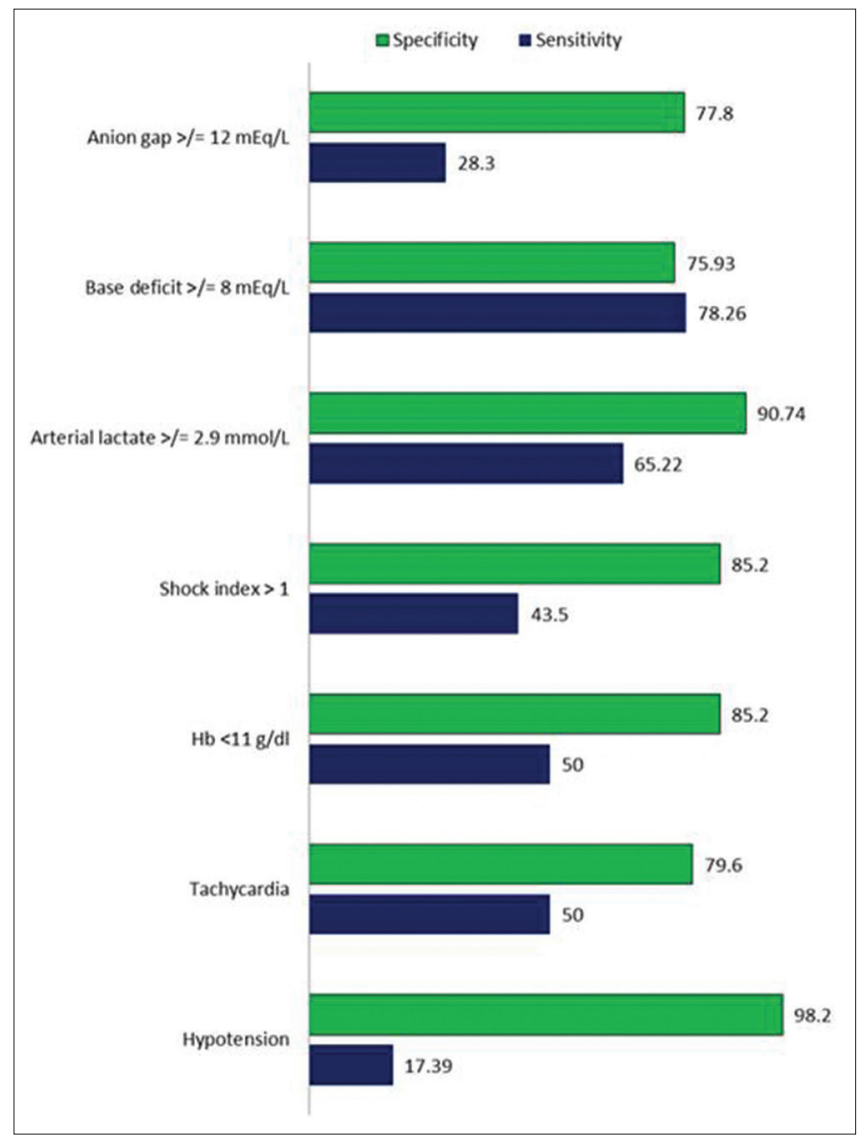

Figure 10: Specificity and sensitivity for $24 \mathrm{~h}$ blood transfusion requirement for various clinical and laboratory parameters

Table 4: Correlation of outcomes with biochemical markers

\begin{tabular}{lcccc}
\hline Parameter & Value & 24 h mortality (\%) & 24 h blood transfusion (\%) & ICU admission (\%) \\
\hline Arterial lactate & $\geq 4 \mathrm{mmol} / \mathrm{L}$ & 38.1 & 90.5 & 86.9 \\
& $<4 \mathrm{mmol} / \mathrm{L}$ & 0 & 34.2 & 25.9 \\
BD & $\geq 12 \mathrm{mEq} / \mathrm{L}$ & 30.4 & 78.3 & 91.3 \\
& $<12 \mathrm{mEq} / \mathrm{L}$ & 1.3 & 36.4 & 35.1 \\
\hline
\end{tabular}

BD: Base deficit; ICU: Intensive Care Unit

Table 5: Comparison of base deficit cutoff for mortality in different studies

\begin{tabular}{lccccc}
\hline & $\begin{array}{c}\text { Cutoff: BD more } \\
\text { than (mEq/L) }\end{array}$ & Sensitivity (\%) & Specificity (\%) & $\begin{array}{c}\text { Positive predictive } \\
\text { value (\%) }\end{array}$ & $\begin{array}{c}\text { Negative predictive } \\
\text { value (\%) }\end{array}$ \\
\hline Our study (24 h mortality) & 12 & 87.5 & 82.6 & 30.43 & 98.7 \\
Saad et al. ${ }^{[14]}$ (mortality) & 5.6 & 64 & 93 & 59.5 & 94.2 \\
Mofidi el.$^{[15]}$ (mortality) & 6 & 88.2 & 95.2 & 79 & 97.5 \\
\hline
\end{tabular}

BD: Base deficit 
used. They found lactate is significantly better than Standard Triage Criteria in all patients and was most useful in victims of blunt trauma, especially motor vehicle collisions. ${ }^{[16]}$

Davis et al. also found that both ICU and hospital length of stay increased with worsening $\mathrm{BD}(P<0.015$ and $P<0.05$, respectively). The frequency of adult respiratory distress syndrome $(P<0.01)$, renal failure $(P=0.015)$, coagulopathy $(P<0.001)$, and multiorgan system failure $(\mathrm{MOF})(P=0.002)$ all increased with increasingly severe BD.

Dunne et al. did a study using multiple logistic and linear regression analyses and confirmed admission lactate and BD as significant independent predictors of mortality, ICU and hospital length of stay $(P<0.01) \cdot{ }^{[17]}$

Arterial lactate and BD measurement are readily available in most emergency departments, and their values at ED admission could help us in deciding their disposition.

\section{Conclusion}

Emergency admission arterial lactate and Base Deficit are useful in predicting $24 \mathrm{~h}$ mortality, blood transfusion requirement and ICU admission. These values can be used to triage, identify shock early, assess transfusion requirement, and prognosticate trauma patients.

\section{Financial support and sponsorship}

Nil.

\section{Conflicts of interest}

There are no conflicts of interest.

\section{References}

1. Krug EG, Mercy JA, Dahlberg LL, Zwi AB. The world report on violence and health. Lancet 2002;360:1083-8.

2. World Health Organization. World Health Statistics: Cause-Specific Mortality and Morbidity. World Health Organization; 2009.

3. American College of Surgeons. Committee on Trauma. Advanced Trauma Life Support: ATLS: Student Course Manual. $9^{\text {th }}$ ed. American College of Surgeons; 2012.
4. Paladino L, Sinert R, Wallace D, Anderson T, Yadav K, Zehtabchi S, et al. The utility of base deficit and arterial lactate in differentiating major from minor injury in trauma patients with normal vital signs. Resuscitation 2008;77:363-8.

5. Das AK, Gupta SB, Joshi SR, Aggarwal P, Murmu LR, Bhoi S, et al. White paper on academic emergency medicine in India: INDO-US Joint Working Group (JWG). J Assoc Physicians India 2008;56:789-98.

6. Kruse O, Grunnet N, Barfod C. Blood lactate as a predictor for in-hospital mortality in patients admitted acutely to hospital: A systematic review. Scand J Trauma Resusc Emerg Med 2011;19:74.

7. Okello M, Makobore P, Wangoda R, Upoki A, Galukande M. Serum lactate as a predictor of early outcomes among trauma patients in Uganda. Int J Emerg Med 2014;7:20.

8. Odom SR, Howell MD, Silva GS, Nielsen VM, Gupta A, Shapiro NI, et al. Lactate clearance as a predictor of mortality in trauma patients. J Trauma Acute Care Surg 2013;74:999-1004.

9. Arslan A, Flax L, Fraser R, Kanter M, Simon R, Caputo ND, et al. Twenty-four-hour packed red blood cell requirement is the strongest independent prognostic marker of mortality in ED trauma patients. Am J Emerg Med 2016;34:1121-4.

10. Brooke M, Yeung L, Miraflor E, Garcia A, Victorino GP. Lactate predicts massive transfusion in hemodynamically normal patients. J Surg Res 2016;204:139-44

11. Rixen D, Raum M, Bouillon B, Lefering R, Neugebauer E, Arbeitsgemeinschaft "Polytrauma" of the Deutsche Gesellschaft fur Unfallchirurgie, et al. Base deficit development and its prognostic significance in Posttrauma critical illness: An analysis by the trauma registry of the Deutsche Gesellschaft für Unfallchirurgie. Shock 2001;15:83-9.

12. Davis JW, Kaups KL, Parks SN. Base deficit is superior to $\mathrm{pH}$ in evaluating clearance of acidosis after traumatic shock. J Trauma 1998;44:114-8.

13. Mutschler M, Nienaber U, Brockamp T, Wafaisade A, Fabian T, Paffrath T, et al. Renaissance of base deficit for the initial assessment of trauma patients: A base deficit-based classification for hypovolemic shock developed on data from 16,305 patients derived from the TraumaRegister DGU®. Crit Care 2013;17:R42.

14. Saad S, Mohamed N, Moghazy A, Ellabban G, El-Kamash S. Venous glucose, serum lactate and base deficit as biochemical predictors of mortality in patients with polytrauma. Ulus Travma Acil Cerrahi Derg 2016;22:29-33.

15. Mofidi M, Hasani A, Kianmehr N. Determining the accuracy of base deficit in diagnosis of intra-abdominal injury in patients with blunt abdominal trauma. Am J Emerg Med 2010;28:933-6.

16. Lavery RF, Livingston DH, Tortella BJ, Sambol JT, Slomovitz BM, Siegel JH, et al. The utility of venous lactate to triage injured patients in the trauma center. J Am Coll Surg 2000;190:656-64.

17. Dunne JR, Tracy JK, Scalea TM, Napolitano LM. Lactate and base deficit in trauma: Does alcohol or drug use impair their predictive accuracy? J Trauma 2005;58:959-66. 